\title{
Longitudinal white-matter abnormalities in sports-related concussion
}

\author{
A diffusion MRI study
}

Yu-Chien Wu, MD, PhD, DABMP, Jaroslaw Harezlak, PhD, Nahla M. H. Elsaid, PhD, Zikai Lin, MS, Qiuting Wen, PhD, Sourajit M. Mustafi, PhD, Larry D. Riggen, MS, Kevin M. Koch, PhD, Andrew S. Nencka, PhD, Timothy B. Meier, PhD, Andrew R. Mayer, PhD, Yang Wang, MD, PhD, Christopher C. Giza, MD, John P. DiFiori, MD, FACSM, Kevin M. Guskiewicz, PhD, ATC, Jason P. Mihalik, PhD, CAT(C), ATC, Stephen M. LaConte, PhD, Stefan M. Duma, PhD, Steven P. Broglio, PhD, ATC, Andrew J. Saykin, PsyD, ABCN, Michael A. McCrea, PhD, ABPP, and Thomas W. McAllister, MD

Neurology ${ }^{\circledR}$ 2020;95:e781-e792. doi:10.1212/WNL.0000000000009930

\section{Abstract}

\section{Objective}

To study longitudinal recovery trajectories of white matter after sports-related concussion (SRC) by performing diffusion tensor imaging (DTI) on collegiate athletes who sustained SRC.

\section{Methods}

Collegiate athletes $(n=219,82$ concussed athletes, 68 contact-sport controls, and 69 non-contactsport controls) were included from the Concussion Assessment, Research and Education Consortium. The participants completed clinical assessments and DTI at 4 time points: 24 to 48 hours after injury, asymptomatic state, 7 days after return-to-play, and 6 months after injury. Tract-based spatial statistics was used to investigate group differences in DTI metrics and to identify whitematter areas with persistent abnormalities. Generalized linear mixed models were used to study longitudinal changes and associations between outcome measures and DTI metrics. Cox proportional hazards model was used to study effects of white-matter abnormalities on recovery time.

\section{Results}

In the white matter of concussed athletes, DTI-derived mean diffusivity was significantly higher than in the controls at 24 to 48 hours after injury and beyond the point when the concussed athletes became asymptomatic. While the extent of affected white matter decreased over time, part of the corpus callosum had persistent group differences across all the time points. Furthermore, greater elevation of mean diffusivity at acute concussion was associated with worse clinical outcome measures (i.e., Brief Symptom Inventory scores and symptom severity scores) and prolonged recovery time. No significant differences in DTI metrics were observed between the contact-sport and non-contact-sport controls.

\section{Conclusions}

Changes in white matter were evident after SRC at 6 months after injury but were not observed in contact-sport exposure. Furthermore, the persistent white-matter abnormalities were associated with clinical outcomes and delayed recovery time.

\author{
Correspondence \\ Dr. Wu \\ yucwu@iu.edu
}

RELATED ARTICLE

\section{Editorial}

White matter and concussion: Are we on the right tract?

Page 279

From the Departments of Radiology and Imaging Sciences (Y.-C.W., N.M.H.E., Q.W., S.M.M., A.J.S.), Psychiatry (Z.L., T.W.M.), and Biostatistics (L.D.R.), Indiana University School of Medicine, Indianapolis; Department of Epidemiology and Biostatistics (J.H.), School of Public Health, Indiana University, Bloomington; Nanoscope Technology LLC (S.M.M.), Bedford, TX; Departments of Radiology (K.M.K., A.S.N., Y.W.) and Neurosurgery (T.B.M., M.A.M.), Medical College of Wisconsin, Milwaukee; The Mind Research Network (A.R.M.), Albuquerque, NM; Department of Neurosurgery (C.C.G.), David Geffen School of Medicine at the University of California Los Angeles; Division of Pediatric Neurology (C.C.G.), Mattel Children's Hospital-UCLA; Departments of Family Medicine and Orthopedics (J.P.D.), Division of Sports Medicine, University of California Los Angeles; Primary Care Sports Medicine (J.P.D.), Hospital for Special Surgery, New York, NY; Matthew Gfeller Sport-Related Traumatic Brain Injury Research Center (K.M.G., J.P.M.), Department of Exercise and Sport Science, University of North Carolina, Chapel Hill; School of Biomedical Engineering and Sciences (S.M.L.), Wake-Forest and Virginia Tech University, Virginia Tech Carilion Research Institute, Roanoke; School of Biomedical Engineering and Sciences (S.M.D.), Wake-Forest and Virginia Tech University, Blacksburg; and NeuroTrauma Research Laboratory (S.P.B.), Michigan Concussion Center, University of Michigan, Ann Arbor.

Go to Neurology.org/N for full disclosures. Funding information and disclosures deemed relevant by the authors, if any, are provided at the end of the article. 


\section{Glossary}

AD = axial diffusivity; ARC = Advanced Research Core BESS = Balance Error Scoring System BSI = Brief Symptom Inventory; CARE = Concussion Assessment, Research and Education; DoD = Department of Defense; DTI = diffusion tensor imaging; FA = fractional anisotropy; FSL = FMRIB Software Library; $M D=$ mean diffusivity; NCAA $=$ National Collegiate Athletic Association; RD = radial diffusivity; ROI = region-of-interest; SRC = sports-related concussion; $\mathbf{T B S S}=$ tract-based spatial statistical; UCLA = University of California Los Angeles; UNC = University of North Carolina; VT = Virginia Tech.

Sports-related concussion (SRC) is a serious public health issue. According to estimates by the Centers for Disease Control, each year, 1.6 to 3.8 million concussions occur in sport- and recreation-related injuries among high school and collegiate athletes. ${ }^{1,2}$ While standardized assessment tools are useful in the clinical management of SRC, ${ }^{3}$ the natural history of SRC and the time course of pathophysiologic recovery remain unclear. ${ }^{4,5}$

MRI, a safe and noninvasive imaging technique, is especially suitable for detecting pathophysiologic changes after SRC and monitoring progression. While conventional clinical MRI methods have difficulty detecting changes in white matter after SRC, diffusion tensor imaging (DTI), a method for probing white-matter microarchitecture, has demonstrated adequate diagnostic sensitivity to acute changes of the brain after SRC. ${ }^{6}$ Similarly, we have previously shown that mean diffusivity (MD), a DTI metric describing averaged water diffusion in tissue, was higher in concussed athletes and associated with clinical symptoms at acute concussion.?

Historically, large prospective longitudinal studies on SRC have been difficult due to low incidence rates $(<1$ per 1,000 athlete exposures $)^{2}$ and challenges in proper identification of concussion. There are only a few studies on longitudinal changes in DTI metrics after SRC. ${ }^{5,8-12}$ In the present study, we investigated longitudinal white-matter alterations using DTI and clinical data from a large national multicenter study, the Concussion Assessment, Research and Education (CARE) Consortium. We hypothesized that white-matter abnormalities as in elevated DTI-derived MD persist beyond the point when athletes became clinically asymptomatic (i.e., cleared to begin their return-to-play protocol) and that white-matter abnormalities would be associated with clinical outcomes and recovery time.

\section{Methods}

\section{Study cohorts}

The participants were recruited in a multisite study of the natural history of concussion conducted through the National Collegiate Athletic Association (NCAA)-Department of Defense (DoD) CARE Consortium Advanced Research Core (ARC) ${ }^{13}$ Study sites included in this analysis are the University of North Carolina (UNC), the University of California Los Angeles (UCLA), and Virginia Tech (VT). A total of 219 collegiate athletes who completed the CARE protocol by July 2018 were included in this study. There were 3 cohorts: 82 athletes diagnosed with concussion, 68 matched contact-sport controls, and 69 matched non-contact-sport controls. The concussed and contact-sport athletes were from the football, soccer, and lacrosse teams. The non-contact-sport controls were from the baseball, softball, basketball, track and field, and cross-country teams. Contact-sport and non-contact-sport controls were matched to concussed athletes on the variables of age, sex, education, and estimated premorbid level of verbal intellectual functioning (i.e., Wechsler Test of Adult Reading ${ }^{14}$ ). For contact-sport controls, additional matching variables included the number of prior concussions, types of sport, and position.

\section{Standard protocol approvals, registrations, and patient consents}

All participants provided informed consent approved by the Medical College of Wisconsin Institutional Review Board and the Human Research Protection Office. The Institutional Review Board protocol number is PRO23196.

\section{Longitudinal study design}

All participants received baseline clinical assessments when recruited into the CARE-ARC study. Concussed athletes received clinical assessments ${ }^{13}$ and multimodal MRI scans ${ }^{15}$ at 4 time points: (1) 24 to 48 hours after injury, (2) the point at which the concussed athletes became asymptomatic (cleared for return-to-play progression), (3) 7 days after unrestricted return to play, and (4) 6 months after injury. When the concussed athletes became asymptomatic, they started a stepwise exercise progression protocol of 5 rehabilitation stages that had to be completed before unrestricted return to play. The return-to-play progression protocol followed the recommendations outlined in the Berlin consensus statement. ${ }^{16}$ For simplicity, hereafter we label the 4 time points as time points 1,2,3, and 4 . In addition to clinical assessments, the interval from injury to asymptomatic state (i.e., time to asymptomatic) and the interval from injury to unrestricted return to play (i.e., time to return to play) were used as indicators of recovery trajectory. The 2 matched control groups received the same clinical assessments and MRI scans at similar time intervals. All participants underwent MRI scans on the same day as clinical assessments.

\section{Clinical assessments}

Clinical assessments followed the CARE Consortium study protocol. ${ }^{13}$ The comprehensive battery of clinical outcome measures included the Standardized Assessment of Concus$\operatorname{sion}^{17}$ to assess cognition, the Sports Concussion Assessment Tool $^{4}$ to assess symptom and symptom severity, the Balance 
Error Scoring System (BESS) ${ }^{18}$ to assess postural stability, and the Brief Symptom Inventory $(\mathrm{BSI})^{19}$ to assess psychological health. The BSI can be further divided into 3 subcategories: BSI-soma for somatic symptoms and BSI-anxiety and BSIdepression for evaluating affective symptoms. Thus, a total of 8 clinical measures were studied for longitudinal clinical recoveries, associations with white-matter abnormalities, and predictions of persistent postinjury white-matter changes.

\section{Diffusion imaging protocol}

Diffusion MRI was performed on the participants on Siemens MAGNETOM 3T Tim Trio (VT, UNC, and UCLA; Siemens, Munich, Germany) or 3T Prisma (UNC and UCLA) scanners across 3 ARC sites with a 12-channel (VT) or 32channel (UNC and UCLA) receiver-only head coil. A singleshot echo planar imaging sequence with a twice-refocused spin echo was used. The diffusion-encoding scheme consisted of 30 directions at a $b$ value of $1,000 \mathrm{~s} / \mathrm{mm}^{2}$ and $8 b_{0}$ (b value $\left.=0 \mathrm{~s} / \mathrm{mm}^{2}\right)$. One of the $b_{0}$ volumes was acquired with a reversed phase-encoding direction.

Care has been taken to ensure the quality and stability of the longitudinal diffusion MRI signal. Three quality assurance/ quality control-related studies were performed before this study to ensure the MRI quality and to evaluate cross-site DTI signal stability. These studies included physical phantom scans, traveling human phantom scans, and analyses of non-contactsport controls across sites. ${ }^{7,15,20}$ For physical phantom scans, each imaging site performs the phantom study periodically and before and after the scanner upgrade. For diffusion MRI, the phantom study used a Function Biomedical Informatics Research Network gel phantom to detect the geometric distortion, eddy current distortion, and k-space spike artifacts. For traveling human phantom scans, to evaluate cross-site reproducibility and reliability, 2 traveling human phantoms visited each site, where they received repeated scans for test-retest evaluation. ${ }^{15}$ In analyses of non-contact-sport controls, coefficients of variation of DTI metrics in non-contact-sport controls were evaluated.

\section{Image processing}

We used the same diffusion image processing pipelines as that used in a previous study. ${ }^{7}$ All the raw and motion-corrected diffusion-weighted images were inspected by a single trained researcher (S.M.M.). Two datasets (UCLA_FB_2016 and UCLA_FB_2017) (of 721) that had severe motion artifacts beyond correction were excluded. Diffusion image processing included preprocessing followed by computation of DTI metrics. The diffusion-weighted images were first denoised with the local principal component analysis approach. ${ }^{21}$ Unlike conventional denoising methods by smoothing the image, the local principal component analysis denoising approach does not sacrifice the image spatial resolution. With a pair of reversephase-encoded $b_{0}$ images as reference, the diffusion-weighted images were then corrected for motion, eddy current artifacts, and static-field geometric distortion with the eddy_openmp command provided in the FMRIB Software Library (FSL). ${ }^{22}$
The FSL eddy command detects outliers slice by slice with gaussian process predictions. After the image preprocessing, DTI metrics were computed voxel-wise with a linear fitting algorithm using the FSL dtifit command. Maps of DTI metrics were transformed to the standard Montreal Neurological Institute space with the use of Advanced Neuroimaging Tools nonlinear registration. $^{23}$

\section{Interpretation of DTI metrics}

Four DTI metrics were included in this study (figure e-1, data available from Dryad, doi:10.5061/dryad.sn02v6x13): MD describing the speed of water movement (i.e., diffusion) in the brain tissue regardless of the directionality, radial diffusivity (RD) describing diffusion perpendicular to the axonal axis, axial diffusivity $(\mathrm{AD})$ describing diffusion parallel to axons, and fractional anisotropy (FA) describing the variance among the eigenvalues of the diffusion tensor. An abnormal increase in MD may indicate destruction of the tissue microarchitectures such as axonal beading, cellular swelling, demyelination, or brain edema. An abnormal increase in $\mathrm{RD}$ indicates structural destruction perpendicular to the axons such as demyelination, while an abnormal increase in $\mathrm{AD}$ indicates structural destruction parallel to the axons such as destruction of cytoskeletons. An abnormal decrease in FA may indicate disorganization of axons or demyelination (table e-1, data available from Dryad).

\section{Tract-based spatial statistical analyses}

Tract-based spatial statistical (TBSS) was used to test for between-group differences in the DTI metrics at each time point. In the standard Montreal Neurological Institute space, a common whole-brain white-matter skeleton was extracted with the FSL toolbox. ${ }^{24}$ Within the white-matter skeleton, nonparametric permutation-based statistics used in TBSS (i.e., the randomise command) was used for voxel-wise statistical analysis. A threshold-free cluster enhancement ${ }^{25}$ and 5,000 permutations ${ }^{26}$ were used in this study. White-matter voxels were deemed significant if $p<0.05$ after adjustment for multiple comparisons by controlling the family-wise error rate. The general regression models used in TBSS were adjusted for age, sex, site, scanner, and receiver-coil differences.

\section{Region-of-interest analyses}

Region-of-interest (ROI) analyses were used to study longitudinal changes in the DTI metrics across the time points and associations of the diffusion metrics with clinical outcomes. Each of the TBSS regression analyses produced white-matter voxels that had significant differences in the DTI metrics between study cohorts. These voxels were collected and intersected across time points to generate a white-matter ROI in which DTI metrics had persistent between-group differences from acute concussion to 6 months after injury. Means of the DTI metrics in the persistent white-matter ROI were computed for each participant to study (1) longitudinal whitematter changes, (2) correlations with outcome assessment scores at the same time points, (3) associations with outcome assessment at different time points using a prediction model 
(see Statistical Analyses section), and (4) associations with recovery rates measured by time to asymptomatic state and time to return to play.

\section{Statistical analyses}

The following statistical analyses were conducted with R-3.5.1 software (r-project.org, R Foundation for Statistical Computing, Vienna, Austria). Analysis of variance was used to test group differences of continuous variables in demographic and clinical outcome measures (table 1). If the analysis of variance test was significant, post hoc pair-wise tests were performed with Tukey adjustments for multiple comparisons. For categorical variables, $\chi^{2}$ tests were used to assess the differences in sex compositions between groups. To analyze longitudinal changes in outcome measures (figure 1) and diffusion metrics (figure 3, B-D), generalized linear mixed models were used. In particular, the longitudinal trajectories were modeled as a function of group (i.e., concussed, contact-sport control, and non-contact-sport control groups) and time point, as well as their interaction. Contrasts between the groups at each time point (figure 1) and contrasts between time points within a group (figure 3 ) were estimated with a compound symmetry correlation structure. A value of $p<0.05$ was deemed significant after adjustment by the Tukey method for multiple comparisons of groups and time points. Similarly, generalized linear mixed models were used to study associations between the DTI metrics in persistent white-matter and outcome measures at individual time points (figure 4) and across-timepoints associations (table 2). The latter was to infer which outcome measure at the acute time point can best predict white-matter changes in later time points. The clinical recovery times (i.e., time to asymptomatic state and time to return to play) in the concussed athletes were first studied with Kaplan-Meier analyses (figure e-2, data available from Dryad, doi:10.5061/dryad.sn02v6x13). The dependence of recovery time on the DTI metrics was analyzed with the Cox proportional hazards model. DTI metrics were considered to have significant associations with recovery time if their coefficient $p$ values in the model were $<0.05$.

\section{Data availability}

The MRI data and clinical data were collected through the CARE Consortium funded by the NCAA-DoD Grand Alliance. Deidentified data will be made available following the existing data-sharing plans outlined in the CARE Consortium and the Federal Interagency Traumatic Brain Injury Research platform.

\section{Results}

The characteristics of the concussed and control groups are listed in table 1 . The 82 concussed athletes were football $(\mathrm{n}=$ $49)$, soccer $(n=25)$, and lacrosse $(n=8)$ players. The 68 contact-sport controls were teammates of the concussed athletes and consisted 39 football, 23 soccer, and 6 lacrosse players. The sport types of the non-contact-sport controls included baseball $(n=32)$, softball $(n=7)$, basketball $(n=3)$, track and field $(n=2)$, and cross-country $(n=25)$.

\section{Baseline demographics and clinical assessments}

There were no group differences in age, sex compositions, years of participation in primary sport types, and premorbid level of intellectual function measured by the Wechsler Testing of Adult Reading test (table 1). Compared to the other 2 groups, the non-contact-sport controls had slightly more years of education ( $0.43-0.57$ years more; $p<0.03$, table 1$)$. Similar to our previously published results of modest sample sizes, ${ }^{7}$ at the preseason baseline, there were no differences between the concussed and control groups in clinical assessment scores.

\section{Sample sizes}

Similar to many longitudinal studies, not all the baseline participants received clinical assessments and MRI scans at all time points despite our best efforts. Therefore, the sample sizes varied across time points. Table e-2 (data available from Dryad, doi:10.5061/dryad.sn02v6x13) lists the numbers of participants who had both available clinical assessment scores and usable MRI data for each study group at each time point. These sample sizes were used in the statistical analyses for the following results.

\section{Acute postinjury clinical assessments}

At the acute time point (i.e., time point 1), the concussed group performed more poorly than the 2 control groups on all of the clinical outcome measures $(p<0.01$, table 1 and figure 1 ), as expected. The 2 control groups did not differ significantly in the acute assessments $(p>0.30$, table 1 and figure 1$)$.

\section{Recovery time}

After concussion, the average time until an athlete was cleared to begin the return-to-play protocol (i.e., time to asymptomatic state) was 9.34 days $(n=65$, median $=7.60$ days; quartiles $1,3=$ 5.60, 11.90 days; table 1). As demonstrated in the survival curves (figure e-2, available from Dryad, doi:10.5061/dryad. sn $02 \mathrm{v} 6 \mathrm{x} 13$ ), it took $\approx 7.6$ days for $50 \%$ of the concussed athletes to become asymptomatic and to initiate the return-to-play progression procedures. On average, the concussed athletes took 16.23 days $(\mathrm{n}=58$, median $=14.00$ days; quartiles $1,3=$ $9.26,18.00$ days; table 1) from injury to finish stepwise rehabilitation and to return to unrestricted play. The survival analyses demonstrated that $50 \%$ of the concussed athletes returned to unrestricted play between days 13 and 15, and $100 \%$ returned to play by day 27 (figure e-2, available from Dryad).

\section{Longitudinal changes in clinical assessments}

For clinical outcome measures, differences were observed only between the concussed athletes and the controls (figure 1). No significant differences were observed between the 2 control groups (i.e., contact-sport and non-contact-sport controls). The between-group differences in clinical outcome measures were largest at acute concussion (time point 1 ), and most of them decreased to a nonsignificant level at time point 
Table 1 Subject demographics and clinical measures at acute concussion (i.e., 24-48 hours after injury)

\begin{tabular}{|c|c|c|c|c|c|c|c|}
\hline & \multirow{2}{*}{$\begin{array}{l}\text { Concussed, } \\
\text { mean (SD) }\end{array}$} & \multirow{2}{*}{$\begin{array}{l}\text { Contact control, } \\
\text { mean (SD) }\end{array}$} & \multirow{2}{*}{$\begin{array}{l}\text { Noncontact, } \\
\text { mean (SD) }\end{array}$} & \multirow{2}{*}{$\frac{\text { ANOVA }^{a}}{p \text { Value }}$} & \multicolumn{3}{|c|}{ Tukey post-hoc $t$ test } \\
\hline & & & & & $p$ Value $^{b}$ & $p$ Value $^{c}$ & $p$ Value $^{d}$ \\
\hline Demographics at baseline, $n$ & $\mathrm{n}=82$ & $n=68$ & $\mathrm{n}=69$ & & & & \\
\hline Age, $y$ & $18.87(0.93)$ & $18.82(1.26)$ & $19.20(1.22)$ & 0.10 & - & - & - \\
\hline Sex, M:F, $n^{e}$ & $69: 13$ & $54: 14$ & $55: 14$ & 0.70 & - & - & - \\
\hline Education, y & $12.52(0.75)$ & $12.66(1.04)$ & $13.09(1.10)$ & $<10^{-2 i}$ & 0.67 & $<10^{-2 i}$ & $0.03^{i}$ \\
\hline WTAR standard score & $106.04(13.98)$ & $106.30(13.96)$ & $110.53(9.49)$ & 0.12 & - & - & - \\
\hline Years of participation in primary sports & $10.28(3.63)$ & $10.62(3.82)$ & $11.18(3.69)$ & 0.34 & - & - & - \\
\hline Clinical assessments at acute concussion ${ }^{f}$ & $\mathrm{n}=68$ & $n=64$ & $n=63$ & & & & \\
\hline SAC & $26.15(2.59)$ & $27.69(2.06)$ & $27.60(1.85)$ & $<10^{-4 i}$ & $<10^{-4 i}$ & $<10^{-3 i}$ & 0.99 \\
\hline \multicolumn{8}{|l|}{ SCAT } \\
\hline Symptom score & $10.70(6.59)$ & $2.36(3.81)$ & $2.16(2.76)$ & $<10^{-19 i}$ & $<10^{-22 i}$ & $<10^{-2 \mathrm{i} 2}$ & 0.97 \\
\hline Symptom severity score & $26.09(21.83)$ & $3.47(5.59)$ & $3.19(4.84)$ & $<10^{-22 i}$ & $<10^{-22 i}$ & $<10^{-22 i}$ & 0.99 \\
\hline BESS score & $16.11(10.67)$ & $10.41(5.41)$ & $12.11(5.93)$ & $<10^{-2 i}$ & $<10^{-2 i}$ & $0.01^{i}$ & 0.30 \\
\hline BSI score & $6.22(7.29)$ & $1.17(2.29)$ & $0.94(1.90)$ & $<10^{-12 i}$ & $<10^{-9 i}$ & $<10^{-10 \mathrm{i}}$ & 0.87 \\
\hline BSI-somatization score & $2.72(3.19)$ & $0.38(0.81)$ & $0.27(0.68)$ & $<10^{-16 \mathrm{i}}$ & $<10^{-12 i}$ & $<10^{-13 i}$ & 0.79 \\
\hline BSI-anxiety score & $1.61(2.52)$ & $0.36(0.86)$ & $0.40(1.06)$ & $<10^{-4 i}$ & $<10^{-3}$ & $<10^{-3 i}$ & 0.99 \\
\hline BSI-depression score & $1.89(2.76)$ & $0.44(1.42)$ & $0.27(1.02)$ & $<10^{-7 i}$ & $<10^{-5 i}$ & $<10^{-6 \mathrm{i}}$ & 0.84 \\
\hline \multicolumn{8}{|l|}{ Clinical recovery times, $d$} \\
\hline Time to asymptomatic state ${ }^{\mathrm{g}}$ & $9.34(6.60)$ & NA & NA & - & - & - & - \\
\hline Time to unrestricted return to play ${ }^{h}$ & $16.23(11.77)$ & NA & NA & - & - & - & - \\
\hline \multicolumn{8}{|c|}{ 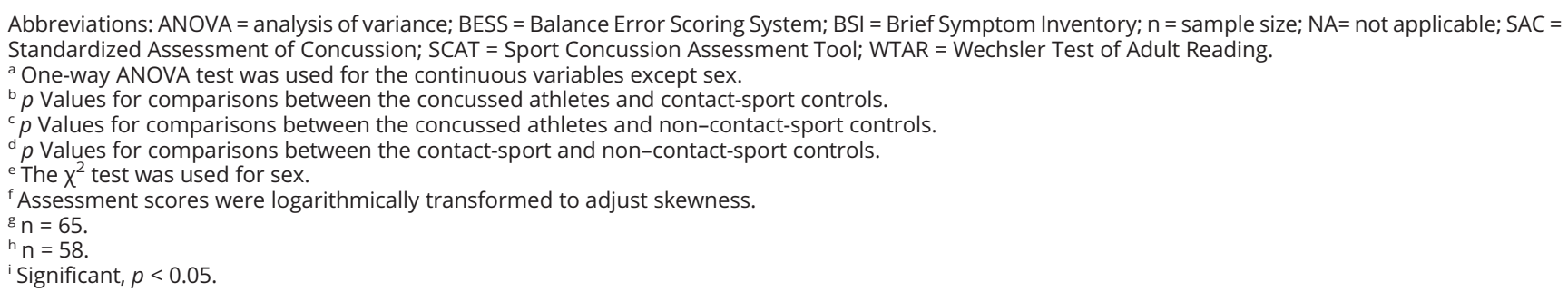 } \\
\hline
\end{tabular}

2 (figure 1). The only measures that had lasting effects at time point 2 were BSI total score and its subcategories BSI-soma and BSI-depression. The clinical assessment scores did not differ between the 3 groups for time points 3 and 4 .

\section{Longitudinal changes in DTI metrics}

The TBSS analyses demonstrated significantly increased MD in the concussed athletes (compared to the 2 control groups) at each time point $(p<0.05$ after controlling for family-wise error rate). White-matter voxels that had significant MD findings between the concussed athletes and contact-sport controls are shown in figure $2 \mathrm{~A}$. The extent of the significant betweengroup white-matter changes decreased over time from 4,834 voxels at time point 1 to 1,763 voxels at time point 4 (figure 2B). $\mathrm{RD}$ was also higher in the concussed athletes but reached significance only at acute concussion (time point 1 ). $\mathrm{AD}$ and
FA did not differ between groups at any time points. Results (not shown) between the concussed athletes and non-contactsport controls were similar. No between-group differences in DTI metrics were observed at each time point between the contact and noncontact control groups.

By intersecting the significant voxels across time points in figure $2 \mathrm{~A}$ (i.e., concussed athletes vs contact controls), a white-matter area of 512 voxels was found to have persistently elevated MD in the concussed athletes (figure 3A). This white-matter area was located in the genu and body of the corpus callosum (based on the Johns Hopkins University white-matter atlas provided in $\left.\mathrm{FSL}^{27}\right)$. In this region, $\mathrm{MD}$ in the concussed athletes was highest at acute concussion $\left(\approx 40 \mathrm{~mm}^{2} / \mathrm{s}\right.$ or $5 \%$ more compared to the controls) and decreased significantly between time points 1 and $2(p<0.05$, asterisk in figure 3B). It reached 

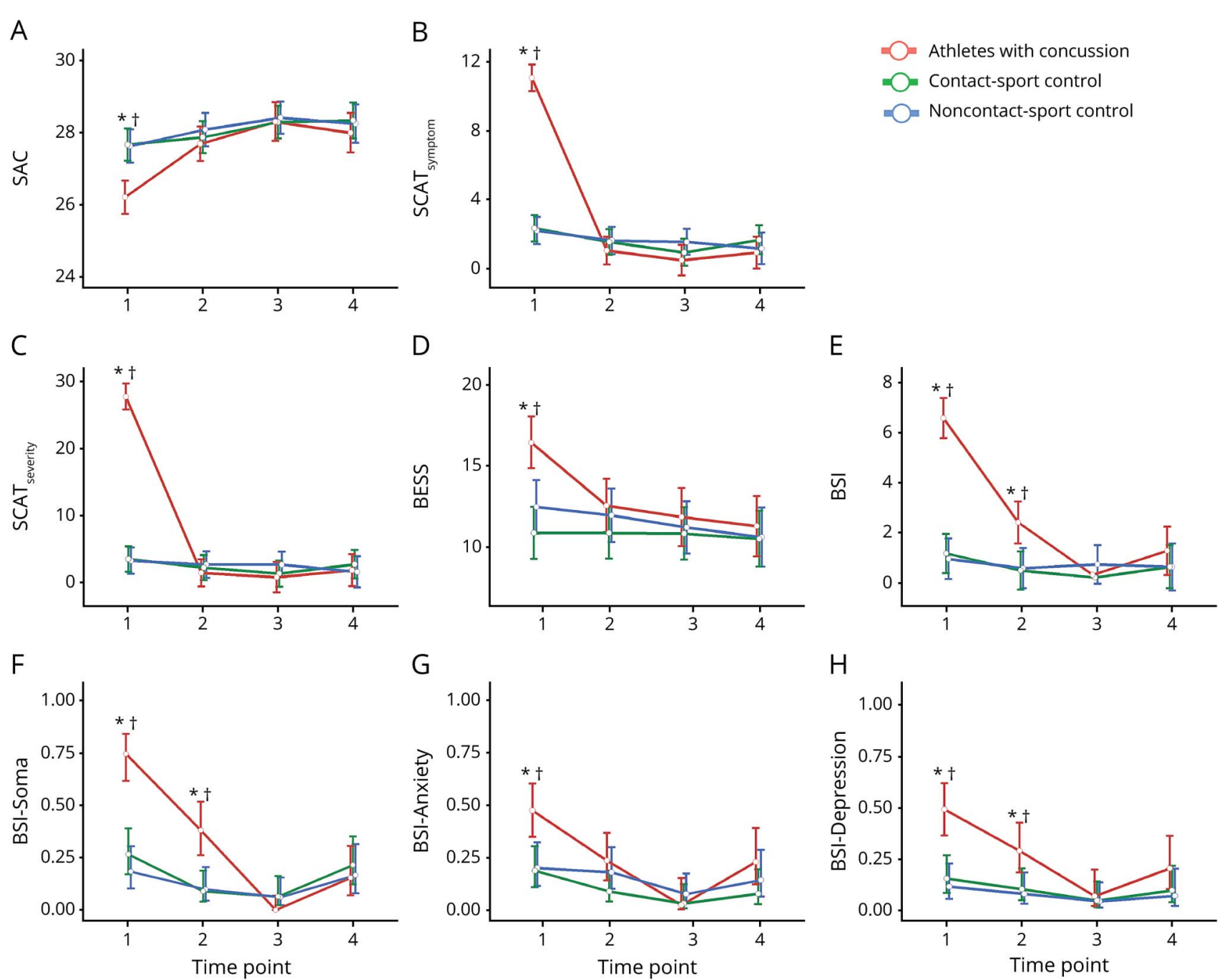

(A) Standard Assessment of Concussion (SAC) scores for the concussed athletes (red), contact-sport controls (green), and non-contact-sport controls (blue) across the 4 time points. Higher SAC scores indicate better performance in the test of cognitive function. (B) Symptom scores in the Sports Concussion Assessment Tool (SCAT) across time points. (C) Symptom severity scores in SCAT. (D) Posture stability scores in the Balance Error Scoring System (BESS). (E) Total psychological distress score in the Brief Symptom Inventory (BSI). (F) BSI subcategory to measure somatization (BSI-soma). (G) BSI subcategory to measure anxiety (BSI-anxiety). (H) BSI subcategory to measure depression (BSI-depression). For SCAT, BESS, and BSI, higher scores indicate worse symptoms. Means and $95 \%$ confidence intervals of the means were plotted for the primary clinical measures (subplots A-E). Mean proportions estimated by the generalized linear mixed model and their respective 95\% confidence intervals were plotted for the BSI subcategories (subplots F-H) because for more than half of the participants, these measures were close to the floor (i.e., zero) at some of the time points. *Significant differences ( $p<0.05$ ) between the concussed athletes and contact-sport controls at the situated time point. †Significant differences $(p<0.05)$ between the concussed athletes and non-contact-sport controls at the situated time point. There were no significant differences detected between the 2 control groups.

a plateau at time point 2 and beyond, at which point no significant temporal differences were found (figure 3B). Similar results were shown for $\mathrm{RD}$ in figure $3 \mathrm{C}$. In the persistently affected white matter, there were no significant temporal changes in the longitudinal trajectories of $\mathrm{AD}$ and FA (figure 3, $\mathrm{D}$ and $\mathrm{E}$, respectively).

In the persistently affected white matter, both $\mathrm{MD}$ and $\mathrm{RD}$ were significantly higher in the concussed athletes than in the 2 control groups. The percentages of differences in $\mathrm{MD}$ between the concussed athletes and contact-sport controls were $5.6 \%$ at time point $1,2.8 \%$ at time point $2,1.8 \%$ at time point 3 , and $1.8 \%$ at time point 4 . The percentages were calculated by subtracting the mean $\mathrm{MD}$ of the contact-sport control group from the mean $\mathrm{MD}$ of the concussed group and then dividing by the mean $\mathrm{MD}$ of the contact-sport control group: $\left(\mathrm{MD}_{\text {concussed }}-\mathrm{MD}_{\text {contact- }}\right.$ sport control $) / \mathrm{MD}_{\text {contact-sport control }} \times 100 \%$. Similarly, the percentages of differences in $\mathrm{RD}$ between the concussed athletes and contact-sport controls were $6.7 \%$ at time point $1,4.0 \%$ at time point $2,2.4 \%$ at time point 3 , and $2.4 \%$ at time point 4 .

\section{Associations between the clinical outcome measures and DTI metrics}

\section{At the same time point}

Within the concussed athletes, higher psychological symptoms (BSI total score and BSI-soma subscale) and concussion 
Table 2 Effects of acute clinical assessment scores on later white-matter changes measured by MD and RD

\begin{tabular}{|c|c|c|c|c|c|c|}
\hline \multirow[b]{2}{*}{ Clinical assessments } & \multicolumn{6}{|c|}{ Association $p$ values } \\
\hline & $M D_{t p 2}$ & $\mathrm{RD}_{\mathrm{tp} 2}$ & $M D_{t p 3}$ & $\mathrm{RD}_{\mathrm{tp} 3}$ & $M D_{\text {tp4 }}$ & $\mathbf{R D}_{\mathrm{tp} 4}$ \\
\hline $\mathrm{SAC}_{\mathrm{tp} 1}$ & 0.16 & 0.28 & 0.85 & 0.23 & 0.97 & 0.78 \\
\hline \multicolumn{7}{|l|}{ SCAT } \\
\hline Symptom score $_{\text {tp } 1}$ & 0.78 & 0.39 & $0.09^{a}(+)$ & 0.32 & 0.87 & 0.36 \\
\hline Symptom severity $_{\text {tp } 1}$ & 0.82 & 0.64 & 0.27 & 0.98 & 0.71 & 0.19 \\
\hline $\mathrm{BESS}_{\mathrm{tp} 1}$ & 0.66 & 0.24 & $0.07^{\mathrm{a}}(+)$ & 0.52 & $0.07^{\mathrm{a}}(+)$ & 0.63 \\
\hline BSI total score & 0.28 & 0.21 & 0.39 & 0.49 & 0.92 & 0.71 \\
\hline BSI-somatization $_{\text {tp1 }}$ & 0.48 & 0.69 & 0.60 & 0.10 & $0.04^{\mathrm{b}}(-)$ & 0.95 \\
\hline BSI-anxiety tp1 $_{1}$ & 0.42 & 0.86 & 0.15 & 0.40 & 0.29 & 0.84 \\
\hline BSI-depression $_{\text {tp1 }}$ & 0.75 & 0.88 & 0.54 & $0.09^{a}(-)$ & 0.56 & 0.92 \\
\hline
\end{tabular}

Abbreviations: BESS = Balance Error Scoring System; BSI = Brief Symptom Inventory; DTI = diffusion tensor imaging; MD = mean diffusivity; RD = radial diffusivity; SAC = Standard Assessment of Concussion; SCAT = Sports Concussion Assessment Tool; - = negative association; + = positive association.

Generalized linear mixed models were used to test associations of clinical outcome measures at acute concussion (time point 1 as in subscript tp1) with MD

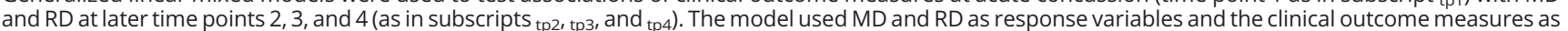
predictors (i.e., independent variables). Primary clinical measures (SAC $\mathrm{tp1}_{1}, \mathrm{SCAT}, \mathrm{BESS} \mathrm{tp1}_{1}$, BSI total score $\mathrm{tp}_{1}$ ) were tested in a single model that automatically adjusted for multiple comparisons across clinical measures and time points. The BSI subcategories were tested separately; thus, their $p$ values were adjusted only within the subcategories and time points.

${ }^{a}$ Marginal significance with $0.05<p<0.1$.

${ }^{\mathrm{b}}$ Significance with $p<0.05$.

symptom severity were associated with higher $M D$ and $R D$ values in the persistently affected white matter at acute concussion $(p<$ 0.01 and $r^{2}>0.49$, figure 4 ). There were no associations between the clinical assessment scores at time points 2,3 , and 4 and the respective DTI metrics at each time point.

\section{Prediction across time points}

The clinical assessment scores at acute concussion were also associated with $\mathrm{MD}$ and $\mathrm{RD}$ in the persistent white matter at later time points (table 2). The associations were strengthened over time with no significant findings at time point $2(p>0.16$, table 2$)$, some marginal significances at time point $3(0.05<p<$ $0.1)$, and significant findings at time point $4(p<0.05)$. In particular, the best clinical outcome predictor for long-term white-matter changes was BSI-soma subscale ( $p=0.04$, table 2 , last column) in which higher scores were associated with lower MD. Multiple comparisons were adjusted across clinical measures and time points, but not $\mathrm{MD}$ and $\mathrm{RD}$. The primary clinical measures (i.e., Standardized Assessment of Concussion, Sports Concussion Assessment Tool, BESS, and BSI total score) were included and tested in a single model that automatically adjusted for multiple comparisons among the clinical measures and time points (i.e., $5 \times 3$ ). Because of strong correlations between the BSI total score and its subcategories, the subcategories (i.e., BSI-soma, BSI-anxiety, and BSI-depression) were tested separately; thus, their $p$ values were adjusted only within the subcategories and time points (i.e., $3 \times 3$ ).

\section{Effects of the DTI metrics on recovery time}

Among the DTI metrics, MD and $\mathrm{RD}$ at the acute time point were significantly associated with recovery time (hazard ratio $p$
$<0.05)$. As MD increased, the Kaplan-Meier curves for recovery time shifted to the right (figure 5). In particular, as $\mathrm{MD}$ increased from 660 to $780 \mathrm{~mm}^{2} / \mathrm{s}$, the time required for $50 \%$ of the concussed athletes to reach asymptomatic state increased from 3 to 12 days (figure 5A). Under extreme conditions, e.g., $\mathrm{MD}>780 \mathrm{~mm}^{2} / \mathrm{s}$, the model extrapolated a chance of at least $7 \%$ that the concussed athletes will never achieve asymptomatic state (figure 5A, blue and pink curves). Note that in this study, the concussed athletes had a mean $\mathrm{MD}$ of $750 \mathrm{~mm}^{2} / \mathrm{s}$, whereas the control groups had a mean $\mathrm{MD}$ of $\approx 710 \mathrm{~mm}^{2} / \mathrm{s}$ at acute concussion (figure 3B). Similarly, for time to return to play, as MD increased from 660 to $780 \mathrm{~mm}^{2} / \mathrm{s}$, the interval from injury to unrestricted return to play for $50 \%$ of the concussed athletes increased from 8 to 17 days (figure 5B).

\section{Discussion}

In this study, we demonstrated that white-matter differences persist beyond the point when the concussed athletes were cleared to return to play (time point 3 ). While clinical assessment scores in the concussed athletes recovered to a level similar to that of the controls at the asymptomatic state (time point 2) by design, the white matter of the concussed athletes had elevated MD at the asymptomatic point and out to 6 months after injury. The extent of affected white matter, however, decreased over time, suggesting partial recovery or at least restoration of the white-matter microstructure. Nevertheless, we observed a small, but statistically significant, whitematter area in the corpus callosum, where MD was persistently higher in the concussed athletes across all the time points. 
Figure 2 Results of group differences in the DTI metrics between the concussed athletes and contactsport controls

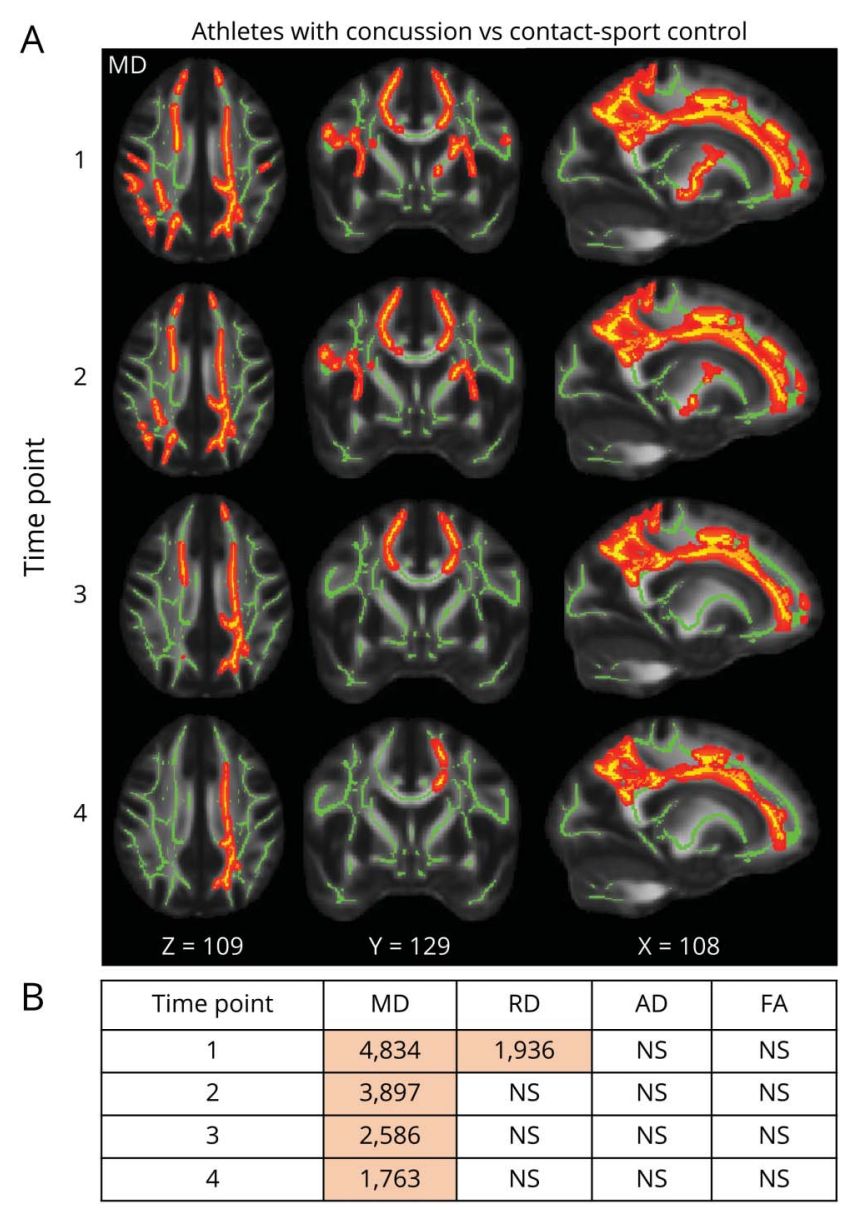

(A) Maps of white-matter voxels (yellow) in which the concussed athletes had significantly elevated mean diffusivity (MD) compared to the contact-sport controls. Tract-based spatial statistics (TBSS) were used with a general linear model; $p<0.05$ adjusted for multiple comparisons with the family-wise error rate was deemed significant. Green voxels denote the white-matter skeleton, where the statistical test was performed. Dark red is background enhancement for illustration purposes. (B) Voxels counts of significant TBSS voxels that had significant group differences (e.g., yellow voxels in A) for DTI metrics, including MD, radial diffusivity (RD), axial diffusivity (AD), and fractional anisotropy (FA). NS = not significant.

The location of the persistently affected white matter (genu and body of the corpus callosum) is consistent with previous publications on acute and chronic SRC. ${ }^{8-10,28,29}$ The corpus callosum contains long-range fibers connecting the left and right hemispheres of the brain. It is unclear whether the physical and biological properties of long fibers make them vulnerable $e^{30-32}$ or their anatomic locations (near the center of mass) make them susceptible to biomechanical forces. ${ }^{33-35}$ Combining finite element analysis, white-matter tractography, and fiber streamline properties may provide further insights.

Our results were consistent with previous studies of modest sample sizes $(\mathrm{n}<30)^{8-12}$ that changes in white matter measured by DTI were detectable even when clinical assessments returned to normal levels. Among these longitudinal studies, the direction of changes in DTI metrics, however, is not consistent. $^{5,8-12}$ Higher MDs were reported in widespread white-matter areas of concussed female athletes $(n=10)$ at long-term time points ( $>7$ months). ${ }^{8}$ On the other hand, decreased $\mathrm{MD}$ was reported in the corticospinal tract of concussed athletes $(\mathrm{n}=16)^{9}$ and widespread white-matter areas of high school football players $(n=17)$ at 6 months after injury. ${ }^{10}$ The remaining studies with no significant findings in $\mathrm{MD}$ also reported inconsistent results in FA and $\mathrm{RD} .^{11,12}$ While DTI metrics are quantitative measures, the discrepancy between studies may stem from differences between studied populations, limited sample sizes, unknown previous exposure/concussion history, differences in DTI acquisition techniques, or image data processing pipelines.

MD of DTI describes an ensemble water diffusion within an imaging voxel, which is of great complexity at the microscopic level and could consist of various tissue compartments. Thus, $\mathrm{MD}$ is sensitive to several pathophysiologic factors, including axonal swelling, extracellular edema, a breakdown of cytoskeleton, demyelination, or decreased viscosity in plasma or extracellular matrix. Increased MD has been observed in different disease mechanisms such as axonal wallerian degeneration, ${ }^{36}$ multiple sclerosis, ${ }^{37}$ vasogenic edema, ${ }^{38}$ tumor-infiltrated edema, ${ }^{39}$ autism, $^{40}$ aging, ${ }^{41}$ and dysmyelination. ${ }^{42}$ Despite only a $5.6 \%$ higher mean value of $\mathrm{MD}$ for the concussed individuals, the significant associations of $\mathrm{MD}$ with clinical outcomes and recovery time suggest that such a change in MD is clinically meaningful.

Although RD was not statistically significant in the TBSS whole-brain analyses except at time point 1 , the average $\mathrm{RD}$ in the persistent white matter (defined by persistently elevated $\mathrm{MD)}$ was significantly higher across all time points in the concussed athletes in the post-hoc Student $t$ test. Inferring from previous animal studies in which $\mathrm{RD}$ was associated with myelin integrity, ${ }^{43,44}$ we suggest that the underlying pathophysiology changes after SRC may involve myelin deterioration. This observation is supported by a prospective cohort study in collegiate hockey players using myelin water fraction MRI in which transient myelin disruption was detected after SRC. ${ }^{45}$

In the persistently affected white matter, if the concussed athletes had higher $\mathrm{MD}$ or $\mathrm{RD}$ at acute concussion, they tended to have worse symptom severity and psychological symptoms. This result is consistent with the previous publication of modest sample size focusing on acute concussion. Higher MD and RD at acute concussion were also associated with longer recovery time. Given the minimal previous studies of the impact of white-matter abnormalities on recovery time, the present results may be of particular importance for future considerations regarding SRC management.

Although no associations were observed between the clinical assessments and DTI metrics other than acute concussion, the 


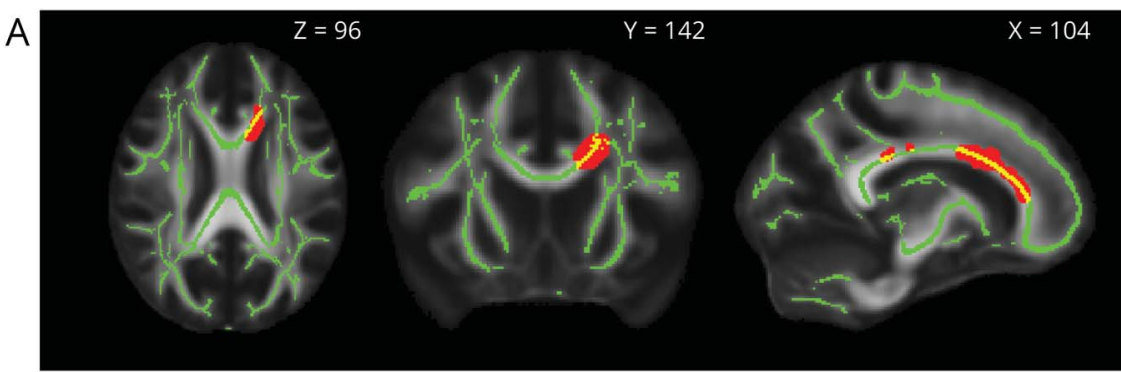

B. MD

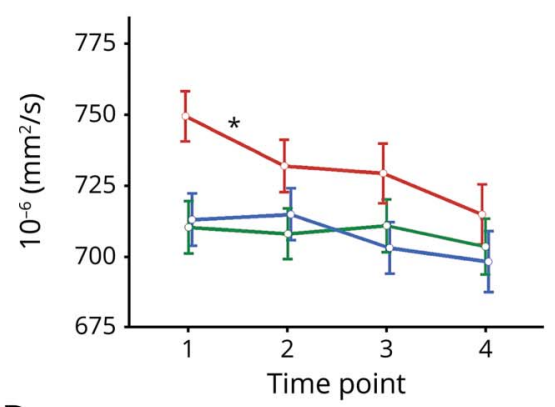

D. $A D$

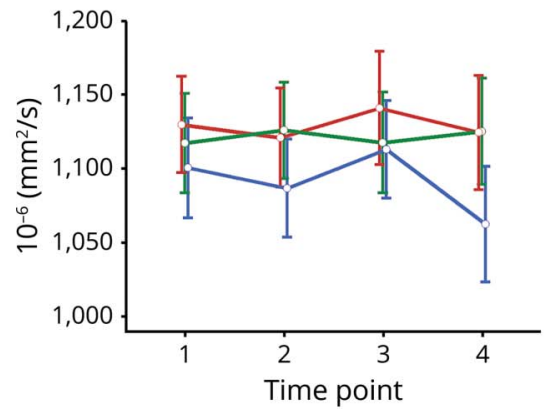

C. RD

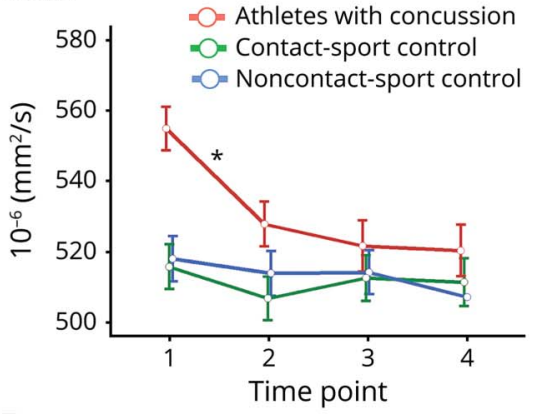

E. FA

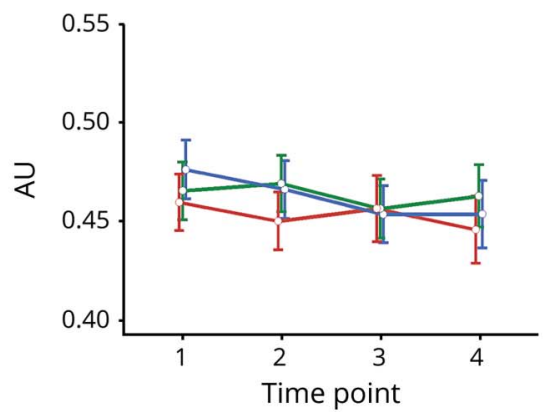

(A) Maps of the persistently affected white matter. Yellow voxels were selected by intersecting the significant voxels across time points in figure 2A. Dark red voxels are background enhancement for illustration purposes. (B) Longitudinal changes of mean diffusivity (MD) in the persistent white matter for the concussed athletes (red), contact-sport controls (green), and non-contactsport controls (blue) across the 4 time points. (C) Longitudinal changes in radial diffusivity (RD). (D) Longitudinal changes in axial diffusivity (AD). (E) Longitudinal changes in fractional anisotropy (FA). Means (circle markers) and 95\% confidence intervals (error bars) of the means were plotted. *Significant differences $(p<0.05)$ in the diffusion tensor imaging (DTI) metrics between the time points within a group. clinical outcome measures acutely after concussion were associated with chronic white-matter changes. This across-timepoint prediction has not been studied or reported before in the literature. Here, we found that the prediction power of the acute clinical measures was enhanced along the course of SRC; the associations progressed from not significant at the asymptomatic state to marginally significant at 7 days after return to play to significant at 6 months after injury. The direction of prediction had mixed results: worse performance on BSI-soma was associated with later low $\mathrm{MD}$, but worse concussion symptom (i.e., high symptom score) and postural stability (i.e., high BESS score) seemed to be associated with later high $\mathrm{MD}$.

BSI-soma and BSI-depression values in the concussed individuals were higher than in controls at the second time point, asymptomatic. In the CARE project and postinjury management, ${ }^{13}$ the asymptomatic time point indicates the time when the concussed athletes are cleared to start a graduated stepwise rehabilitation, called the return-to-play progression program. ${ }^{4}$ The decision about this time point is made by team physicians and medical staff and is based on the SRC assessment battery, clinical evaluations, and neuropsychological tests. While BSI measures are part of the CARE research protocol, they are not commonly used by clinicians in determining an athlete's recovery of postconcussion symptoms and deficits. Thus, some of the concussed athletes may still have higher scores than controls at this time point.

Exposure to contact sports and head impacts has been associated with chronic traumatic encephalopathy, ${ }^{46}$ a neurodegenerative condition that does not yet have validated antemortem diagnostic criteria. ${ }^{47}$ In this study, we did not find significant exposure effects on the white-matter microstructures measured by DTI in a group of athletes with acute and chronic exposure to contact sports. The 2 control groups (i.e., contact-sport controls and non-contact-sport controls) had similar DTI metrics over time, except there was a trend of elevated $\mathrm{AD}$ in the contact-sport controls from the $\mathrm{ROI}$ analyses. A recent study suggested that younger age of exposure in participants with chronic traumatic encephalopathy was associated with earlier neurobehavioral symptom onset. ${ }^{48}$ Thus, future research effort will focus on effects of age at first exposure to contact sport on DTI metrics and interaction 

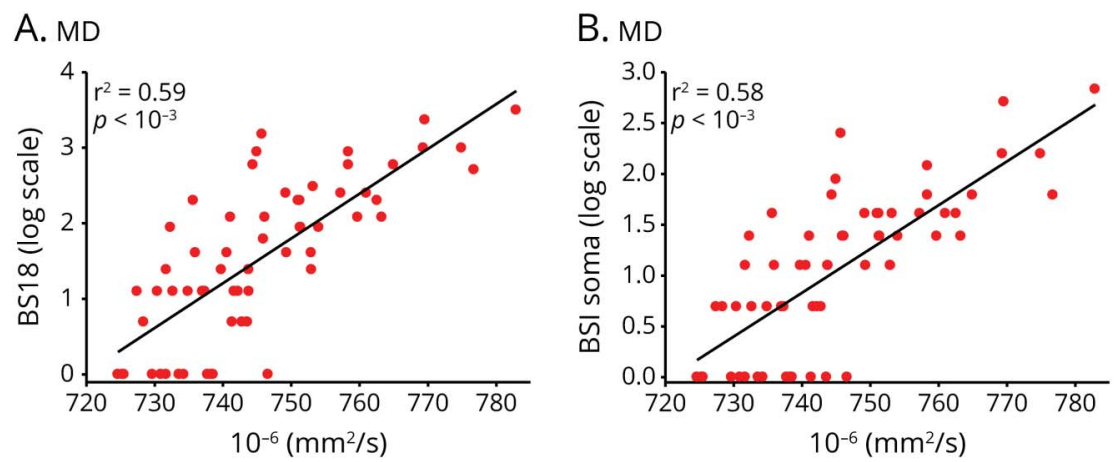

C. MD

D. RD

E. RD
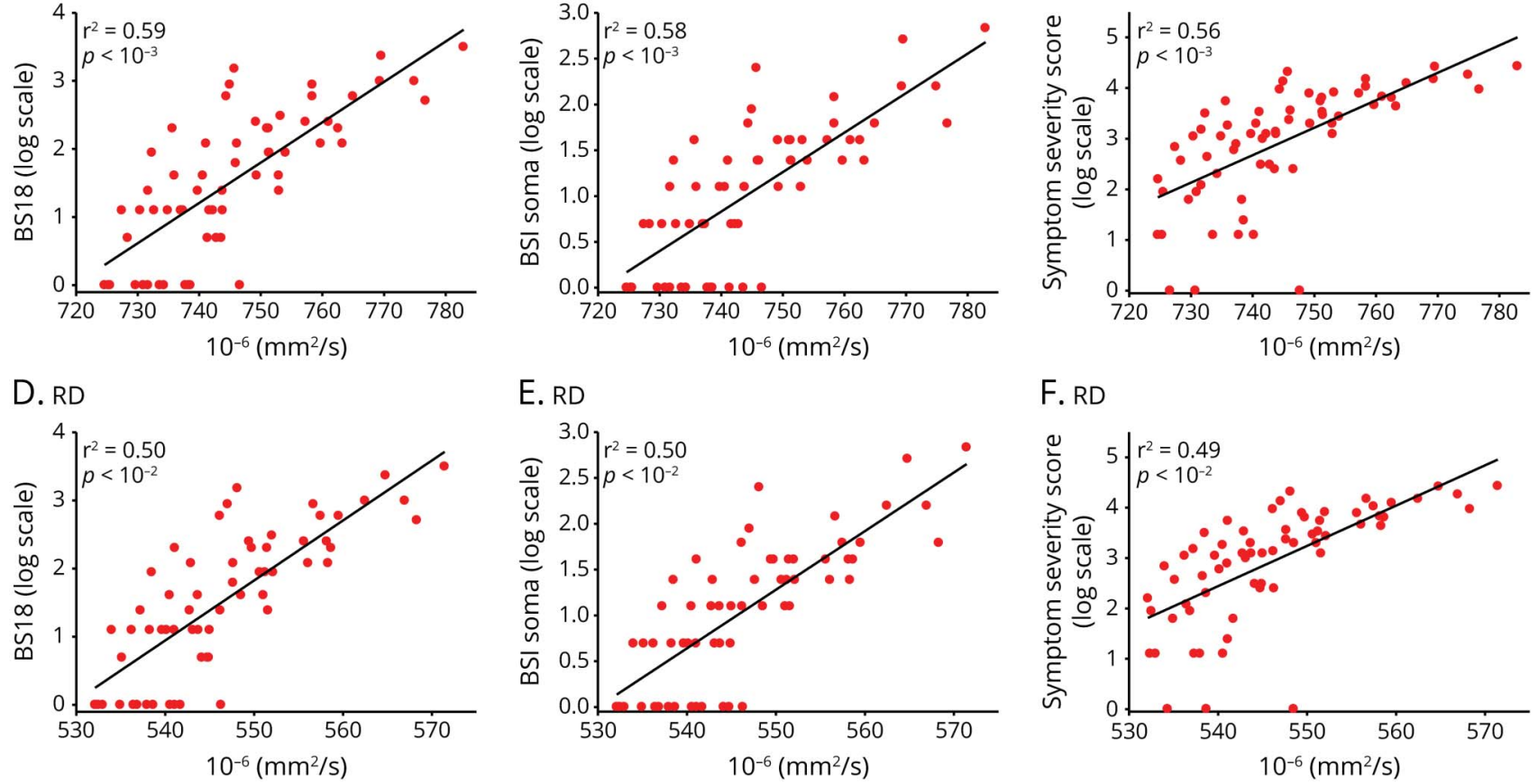

F. RD

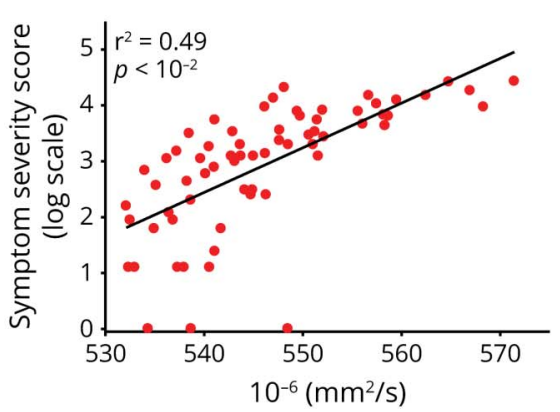

Each red dot denotes 1 individual's clinical assessment scores and means of diffusion tensor imaging (DTI) measurements in the persistently affected white matter (figure 3A). The $r^{2}$ denotes the coefficient of determination, and $p$ denotes the significance of the regression coefficients. Only significant associations $(p<0.05)$ are presented. (A) Brief Symptom Inventory (BSI) total score vs mean diffusivity (MD). BSI total score was logarithmically transformed to eliminate left skewness in the original distribution. (B) Subcategory BSI-somatization vs MD. (C) Symptom severity score in the Sports Concussion Assessment Tool (SCAT) vs MD. (D) BSI total vs radial diffusivity (RD). (E) BSI-somatization vs RD. (F) SCAT symptom severity vs RD.

effects of exposure on associations between the DTI metrics and neurobehavioral outcomes.

Similar to many longitudinal studies, despite our best efforts, there were intermittent missing data across time points. Nevertheless, the missing data (assuming missing at random) were addressed by the generalized linear mixed models that adjusted missingness automatically. ${ }^{49}$ Classic DTI may also limit the study with a gaussian distribution model that makes the interpretation of specific underlying microstructural mechanisms challenging. Furthermore, the directionality of DTI in the white matter was not fully evaluated in this study. Structural connectivity and network analyses may address higher-order questions such as intrinsic characteristics of the topology and communicability of

Figure 5 Dependence of recovery time on MD
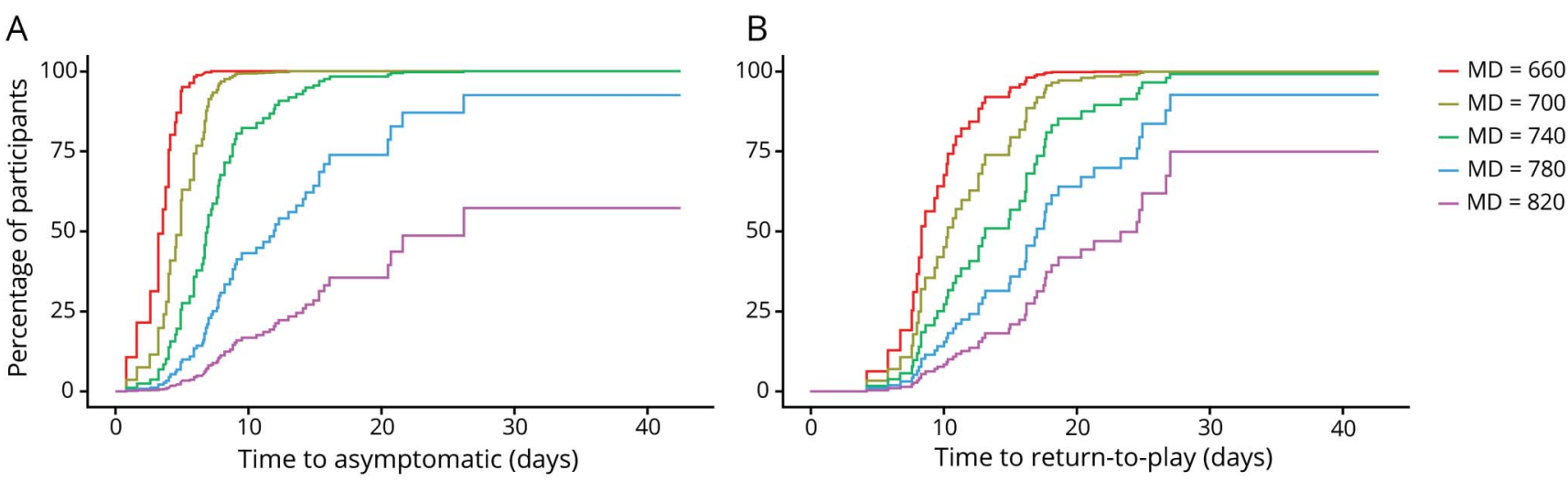

(A) Effect of mean diffusivity (MD) on the survival curves for time to asymptomatic state. (B) Effect of MD on Kaplan-Meier curves for time to unrestricted return to play. Line colors denote different levels of MD with a unit of $10^{-6} \mathrm{~mm}^{2} / \mathrm{s}$. Survival curves to estimate the time to event were modeled with a Cox proportional hazards model with MD as a risk factor. 
the system. ${ }^{50}$ In addition, history of concussion was not included but will be incorporated into future research.

In this prospective study, we demonstrated that SRC has effects on white matter beyond the point when concussed athletes become asymptomatic. There was evidence of norabnormalities up to 6 months after injury. The acute whitematter abnormalities were associated with acute postinjury clinical outcomes and prolonged recovery time.

\section{Acknowledgment}

This publication was made possible, in part, by support from the Grand Alliance CARE Consortium, funded, in part by the NCAA and the DoD. The US Army Medical Research Acquisition Activity, 820 Chandler Street, Fort Detrick, MD 21702-5014, is the awarding and administering acquisition office. This work was supported by the Office of the Assistant Secretary of Defense for Health Affairs through the Psychological Health and Traumatic Brain Injury Program under award W81XWH-14-2-0151. Opinions, interpretations, conclusions and recommendations are those of the author and are not necessarily endorsed by the DoD (DHP funds). The authors thank Jody Harland and Janetta Matesan (Indiana University); Ashley Rettmann (University of Michigan); Melissa Koschnitzke (Medical College of Wisconsin); Michael Jarrett, Vibeke Brinck, and Bianca Byrne (Quesgen); Christy Collins, Melissa Niceley Baker, and Sara Dalton (Datalys Center for Sports Injury Research and Prevention); and the research and medical staff at each of the participating sites. We are grateful for the participation of the student athletes without whom this research would not be possible.

\section{Study funding}

This publication was made possible, in part, by support from the Grand Alliance CARE Consortium, funded, in part by the NCAA and the DoD under award W81XWH-14-2-0151. Other funding support includes NIH grant R21 NS075791 to Y.C.W. and T.W.M., R01 AG053993 to Y.C.W., and P30 AG010133 and R01 AG019771 to A.J.S.

\section{Disclosure}

The authors report no disclosures relevant to the manuscript. Go to Neurology.org/N for full disclosures.

\section{Publication history}

Received by Neurology March 11, 2019. Accepted in final form February 7, 2020.

Appendix Authors

\begin{tabular}{lll}
\hline Name & Location & Contribution \\
\hline Y.C. Wu, MD, & Indiana & Study concept and design, \\
PhD, DABMP & $\begin{array}{l}\text { University School } \\
\text { of Medicine }\end{array}$ & $\begin{array}{l}\text { interpretation of data and results, } \\
\text { drafting manuscript for intellectual } \\
\end{array}$ \\
& $\begin{array}{l}\text { content, and critical revision of the } \\
\text { manuscript for important } \\
\text { intellectual content }\end{array}$
\end{tabular}
malization, but some area of the white matter had persistent

Appendix (continued)

\begin{tabular}{|c|c|c|}
\hline Name & Location & Contribution \\
\hline $\begin{array}{l}\text { J. Harezlak, } \\
\text { PhD }\end{array}$ & $\begin{array}{l}\text { Indiana } \\
\text { University }\end{array}$ & $\begin{array}{l}\text { Study concept and design, } \\
\text { statistical analyses, interpretation } \\
\text { of data, and critical revision of the } \\
\text { manuscript for important } \\
\text { intellectual content }\end{array}$ \\
\hline $\begin{array}{l}\text { S.M. Mustafi, } \\
\text { PhD }\end{array}$ & $\begin{array}{l}\text { Indiana } \\
\text { University School } \\
\text { of Medicine }\end{array}$ & $\begin{array}{l}\text { Data analyses, statistical analyses, } \\
\text { and manuscript preparation }\end{array}$ \\
\hline $\begin{array}{l}\text { N.M.H. Elsaid, } \\
\text { MS }\end{array}$ & $\begin{array}{l}\text { Indiana } \\
\text { University School } \\
\text { of Medicine }\end{array}$ & $\begin{array}{l}\text { Data analyses and interpretation of } \\
\text { data }\end{array}$ \\
\hline Z. Lin, PhD & $\begin{array}{l}\text { Indiana } \\
\text { University School } \\
\text { of Medicine }\end{array}$ & $\begin{array}{l}\text { Statistical analyses and manuscript } \\
\text { preparation }\end{array}$ \\
\hline Q. Wen, PhD & $\begin{array}{l}\text { Indiana } \\
\text { University School } \\
\text { of Medicine }\end{array}$ & $\begin{array}{l}\text { Statistical analyses, interpretation } \\
\text { of data, and manuscript } \\
\text { preparation }\end{array}$ \\
\hline $\begin{array}{l}\text { L.D. Riggen, } \\
\text { MS }\end{array}$ & $\begin{array}{l}\text { Indiana } \\
\text { University School } \\
\text { of Medicine }\end{array}$ & Data analyses \\
\hline $\begin{array}{l}\text { K.M. Koch, } \\
\text { PhD }\end{array}$ & $\begin{array}{l}\text { Medical College } \\
\text { of Wisconsin }\end{array}$ & $\begin{array}{l}\text { Study concept and design, data } \\
\text { acquisition, and critical revision of } \\
\text { the manuscript for important } \\
\text { intellectual content }\end{array}$ \\
\hline $\begin{array}{l}\text { A.S. Nencka, } \\
\text { PhD }\end{array}$ & $\begin{array}{l}\text { Medical College } \\
\text { of Wisconsin }\end{array}$ & $\begin{array}{l}\text { Data acquisition and critical } \\
\text { revision of the manuscript for } \\
\text { important intellectual content }\end{array}$ \\
\hline $\begin{array}{l}\text { T.B. Meier, } \\
\text { PhD }\end{array}$ & $\begin{array}{l}\text { Medical College } \\
\text { of Wisconsin }\end{array}$ & $\begin{array}{l}\text { Study concept, interpretation of } \\
\text { data, and critical revision of the } \\
\text { manuscript for important } \\
\text { intellectual content }\end{array}$ \\
\hline $\begin{array}{l}\text { A.R. Mayer, } \\
\text { PhD }\end{array}$ & $\begin{array}{l}\text { The Mind } \\
\text { Research } \\
\text { Network }\end{array}$ & $\begin{array}{l}\text { Study concept, interpretation of } \\
\text { data, and critical revision of the } \\
\text { manuscript for important } \\
\text { intellectual content }\end{array}$ \\
\hline $\begin{array}{l}\text { Y, Wang, MD, } \\
\text { PhD }\end{array}$ & $\begin{array}{l}\text { Medical College } \\
\text { of Wisconsin }\end{array}$ & $\begin{array}{l}\text { Critical revision of the manuscript } \\
\text { for important intellectual content }\end{array}$ \\
\hline C.C. Giza, MD & $\begin{array}{l}\text { University of } \\
\text { California Los } \\
\text { Angeles }\end{array}$ & $\begin{array}{l}\text { Data acquisition and critical } \\
\text { revision of the manuscript for } \\
\text { important intellectual content }\end{array}$ \\
\hline $\begin{array}{l}\text { J.P. DiFiori, } \\
\text { MD, FACSM }\end{array}$ & $\begin{array}{l}\text { University of } \\
\text { California Los } \\
\text { Angeles }\end{array}$ & $\begin{array}{l}\text { Data acquisition and critical } \\
\text { revision of the manuscript for } \\
\text { important intellectual content }\end{array}$ \\
\hline $\begin{array}{l}\text { K.M. } \\
\text { Guskiewicz, } \\
\text { PhD, ATC }\end{array}$ & $\begin{array}{l}\text { University of } \\
\text { North Carolina }\end{array}$ & $\begin{array}{l}\text { Data acquisition and critical } \\
\text { revision of the manuscript for } \\
\text { important intellectual content }\end{array}$ \\
\hline $\begin{array}{l}\text { J.P. Mihalik, } \\
\text { PhD, CAT(C), } \\
\text { ATC }\end{array}$ & $\begin{array}{l}\text { University of } \\
\text { North Carolina }\end{array}$ & $\begin{array}{l}\text { Data acquisition and critical } \\
\text { revision of the manuscript for } \\
\text { important intellectual content }\end{array}$ \\
\hline $\begin{array}{l}\text { S.M. LaConte, } \\
\text { PhD }\end{array}$ & Virginia Tech & $\begin{array}{l}\text { Data acquisition and critical } \\
\text { revision of the manuscript for } \\
\text { important intellectual content }\end{array}$ \\
\hline $\begin{array}{l}\text { S.M. Duma, } \\
\text { PhD }\end{array}$ & Virginia Tech & $\begin{array}{l}\text { Data acquisition and critical } \\
\text { revision of the manuscript for } \\
\text { important intellectual content }\end{array}$ \\
\hline $\begin{array}{l}\text { S.P. Broglio, } \\
\text { PhD, ATC }\end{array}$ & $\begin{array}{l}\text { University of } \\
\text { Michigan }\end{array}$ & $\begin{array}{l}\text { Study concept and design, } \\
\text { interpretation of data, and critical } \\
\text { revision of the manuscript for } \\
\text { important intellectual content }\end{array}$ \\
\hline
\end{tabular}


Appendix (continued)

\begin{tabular}{lll}
\hline Name & Location & Contribution \\
\hline $\begin{array}{l}\text { A.J. Saykin, } \\
\text { PsyD, ABCN }\end{array}$ & $\begin{array}{l}\text { Indiana } \\
\text { University School } \\
\text { of Medicine }\end{array}$ & $\begin{array}{l}\text { Study concept and design, } \\
\text { interpretation of data, and critical } \\
\text { revision of the manuscript for } \\
\text { important intellectual content }\end{array}$ \\
\hline $\begin{array}{ll}\text { M. McCrea, } \\
\text { PhD, ABPP }\end{array}$ & Medical College & $\begin{array}{l}\text { Study concept and design, } \\
\text { interpretation of data, and critical } \\
\text { revision of the manuscript for } \\
\text { important intellectual content }\end{array}$ \\
\hline $\begin{array}{l}\text { T.W. } \\
\text { McAllister, }\end{array}$ & $\begin{array}{l}\text { University School } \\
\text { MD }\end{array}$ & $\begin{array}{l}\text { Study concept and design, } \\
\text { interpretation of data, and critical } \\
\text { revision of the manuscript for } \\
\text { important intellectual content }\end{array}$ \\
& & indine
\end{tabular}

\section{References}

1. Langlois JA, Rutland-Brown W, Wald MM. The epidemiology and impact of traumatic brain injury: a brief overview. J Head Trauma Rehabil 2006;21:375-378.

2. Daneshvar DH, Nowinski CJ, McKee AC, Cantu RC. The epidemiology of sportrelated concussion. Clin Sports Med 2011;30:1-17, vii.

3. McCrea M, Guskiewicz KM, Marshall SW, et al. Acute effects and recovery time following concussion in collegiate football players: the NCAA Concussion Study. JAMA 2003;290:2556-2563.

4. McCrory P, Meeuwisse W, Dvorak J, et al. Consensus statement on concussion in sport: the 5(th) International Conference on Concussion in Sport held in Berlin, October 2016. Br J Sports Med 2017;51:838-847.

5. Kamins J, Bigler E, Covassin T, et al. What is the physiological time to recovery after concussion? A systematic review. Br J Sports Med 2017;51:935-940.

6. Gardner A, Kay-Lambkin F, Stanwell P, et al. A systematic review of diffusion tensor imaging findings in sports-related concussion. J Neurotrauma 2012;29:2521-2538.

7. Mustafi SM, Harezlak J, Koch KM, et al. Acute white-matter abnormalities in sportsrelated concussion: a diffusion tensor imaging study from the NCAA-DoD CARE Consortium. J Neurotrauma 2018;35:2653-2664.

8. Chamard E, Lassonde M, Henry L, et al. Neurometabolic and microstructural alterations following a sports-related concussion in female athletes. Brain Inj 2013;27: 1038-1046.

9. Henry LC, Tremblay J, Tremblay S, et al. Acute and chronic changes in diffusivity measures after sports concussion. J Neurotrauma 2011;28:2049-2059.

10. Lancaster MA, Meier TB, Olson DV, McCrea MA, Nelson LD, Muftuler LT. Chronic differences in white matter integrity following sport-related concussion as measured by diffusion MRI: 6-month follow-up. Hum Brain Mapp 2018;39:4276-4289.

11. Murugavel M, Cubon V, Putukian M, et al. A longitudinal diffusion tensor imaging study assessing white matter fiber tracts after sports-related concussion. J Neurotrauma 2014;31:1860-1871.

12. Meier TB, Bergamino M, Bellgowan PS, et al. Longitudinal assessment of white matter abnormalities following sports-related concussion. Hum Brain Mapp 2016;37: 833-845.

13. Broglio SP, McCrea M, McAllister T, et al. A national study on the effects of concussion in collegiate athletes and US Military Service Academy members: the NCAA-DoD Concussion Assessment, Research and Education (CARE) Consortium structure and methods. Sports Med 2017;47:1437-1451.

14. Wechsler D. Manual for the Wechsler Adult Intelligence Scale. rev. ed. New York: Pscyhological Corp, Harcourt Brace Janvanovich, Inc; 1987.

15. Nencka AS, Meier TB, Wang Y, et al. Stability of MRI metrics in the advanced research core of the NCAA-DoD Concussion Assessment, Research and Education (CARE) Consortium. Brain Imaging Behav 2018;12:1121-1140.

16. McCrory P, Meeuwisse WH, Aubry M, et al. Consensus statement on concussion in sport: the 4th International Conference on Concussion in Sport, Zurich, November 2012. J Athl Train 2013;48:554-575.

17. McCrea M, Kelly JP, Randolph C. Standardized Assessment of Concussion (SAC): Manual for Administration, Scoring and Interpretation. Waukesha: CNS Inc; 1996.

18. Guskiewicz KM, Ross SE, Marshall SW. Postural stability and neuropsychological deficits after concussion in collegiate athletes. J Athl Train 2001;36:263-273.

19. Derogatis LR. BSI Brief Symptom Inventory: Administration, Scoring, and Procedure Manual. 4th ed. Minneapolis: National Computer Systems; 1993.

20. Lepage C, de Pierrefeu A, Koerte IK, et al. White matter abnormalities in mild traumatic brain injury with and without post-traumatic stress disorder: a subjectspecific diffusion tensor imaging study. Brain Imaging Behav 2018;12:870-881.
21. Manjon JV, Coupe P, Concha L, Buades A, Collins DL, Robles M. Diffusion weighted image denoising using overcomplete local PCA. PLoS One 2013;8:e73021.

22. Andersson JL, Sotiropoulos SN. An integrated approach to correction for offresonance effects and subject movement in diffusion MR imaging. Neuroimage 2016; 125:1063-1078.

23. Avants BB, Tustison NJ, Song G, Cook PA, Klein A, Gee JC. A reproducible evaluation of ants similarity metric performance in brain image registration. Neuroimage 2011;54:2033-2044.

24. Smith SM, Jenkinson M, Johansen-Berg H, et al. Tract-based spatial statistics: voxelwise analysis of multi-subject diffusion data. Neuroimage 2006;31:1487-1505.

25. Smith SM, Nichols TE. Threshold-free cluster enhancement: addressing problems of smoothing, threshold dependence and localisation in cluster inference. Neuroimage 2009;44:83-98.

26. Nichols TE, Holmes AP. Nonparametric permutation tests for functional neuroimaging: a primer with examples. Hum Brain Mapp 2002;15:1-25.

27. Oishi K, Zilles K, Amunts K, et al. Human brain white matter atlas: identification and assignment of common anatomical structures in superficial white matter. Neuroimage 2008;43:447-457.

28. Koerte IK, Kaufmann D, Hartl E, et al. A prospective study of physician-observed concussion during a varsity university hockey season: white matter integrity in ice hockey players, part 3 of 4. Neurosurg Focus 2012;33:1-7.

29. McAllister TW, Ford JC, Flashman LA, et al. Effect of head impacts on diffusivity measures in a cohort of collegiate contact sport athletes. Neurology 2014;82:63-69.

30. Wu YC, Mustafi SM, Harezlak J, et al. Effects of tract length in white matter alterations after sports-related concussion: a diffusion MRI study from the NCAA-DoD CARE Consortium. Presented at the International Society of Magnetic Resonance in Medicine (ISMRM) 27th Annual Meeting; May 11-16, 2019; Montreal.

31. Mustafi SM, Harezlak J, Goni J, Flashman LA, McAllister TW, Wu YC. Effects of track length on white matter alterations in mild traumatic brain injury. In: International Society of Magnetic Resonance in Medicine (ISMRM) 26th Annual Meeting; June 16-21, 2018; Paris.

32. Beckwith JG, Zhao W, Ji S, et al. Estimated brain tissue response following impacts associated with and without diagnosed concussion. Ann Biomed Eng 2018;46: 819-830.

33. Bigler ED. Neuropsychology and clinical neuroscience of persistent post-concussive syndrome. J Int Neuropsychol Soc 2008;14:1-22.

34. Bayly PV, Cohen TS, Leister EP, Ajo D, Leuthardt EC, Genin GM. Deformation of the human brain induced by mild acceleration. J Neurotrauma 2005;22:845-856

35. Viano DC, Casson IR, Pellman EJ, Zhang L, King AI, Yang KH. Concussion in professional football: brain responses by finite element analysis: part 9. Neurosurgery 2005;57:891-916

36. Pierpaoli C, Barnett A, Pajevic S, et al. Water diffusion changes in wallerian degeneration and their dependence on white matter architecture. Neuroimage 2001;13: 1174-1185.

37. Rocca MA, Sonkin M, Copetti M, et al. Diffusion tensor magnetic resonance imaging in very early onset pediatric multiple sclerosis. Mult Scler 2016;22:620-627.

38. Kinoshita M, Goto T, Okita $\mathrm{Y}$, et al. Diffusion tensor-based tumor infiltration index cannot discriminate vasogenic edema from tumor-infiltrated edema. J Neurooncol 2010;96:409-415.

39. Field AS, Alexander AL, Wu YC, Hasan KM, Witwer B, Badie B. Diffusion tensor eigenvector directional color imaging patterns in the evaluation of cerebral white matter tracts altered by tumor. J Magn Reson Imaging 2004;20:555-562.

40. Lee JE, Bigler ED, Alexander AL, et al. Diffusion tensor imaging of white matter in the superior temporal gyrus and temporal stem in autism. Neurosci Lett 2007;424: $127-132$.

41. Westlye LT, Walhovd KB, Dale AM, et al. Life-span changes of the human brain white matter: diffusion tensor imaging (DTI) and volumetry. Cereb Cortex 2010;20: 2055-2068.

42. Wu YC, Field AS, Duncan ID, et al. High b-value and diffusion tensor imaging in a canine model of dysmyelination and brain maturation. Neuroimage 2011;58:829-837.

43. Song SK, Yoshino J, Le TQ, et al. Demyelination increases radial diffusivity in corpus callosum of mouse brain. Neuroimage 2005;26:132-140.

44. Klawiter EC, Schmidt RE, Trinkaus K, et al. Radial diffusivity predicts demyelination in ex vivo multiple sclerosis spinal cords. Neuroimage 2011;55:1454-1460.

45. Wright $\mathrm{AD}$, Jarrett $\mathrm{M}$, Vavasour I, et al. Myelin water fraction is transiently reduced after a single mild traumatic brain injury: a prospective cohort study in collegiate hockey players. PLoS One 2016;11:e0150215.

46. McKee AC, Stern RA, Nowinski CJ, et al. The spectrum of disease in chronic traumatic encephalopathy. Brain 2013;136:43-64.

47. Levin B, Bhardwaj A. Chronic traumatic encephalopathy: a critical appraisal. Neurocrit Care 2014;20:334-344.

48. Alosco ML, Mez J, Tripodis Y, et al. Age of first exposure to tackle football and chronic traumatic encephalopathy. Ann Neurol 2018;83:886-901.

49. Ibrahim JG, Molenberghs G. Missing data methods in longitudinal studies: a review. Test (Madr) 2009; 18:1-43.

50. Sporns O, Betzel RF. Modular brain networks. Annu Rev Psychol 2016;67:613-640. 


\section{Neurology}

\section{Longitudinal white-matter abnormalities in sports-related concussion: A diffusion MRI study}

Yu-Chien Wu, Jaroslaw Harezlak, Nahla M. H. Elsaid, et al.

Neurology 2020;95;e781-e792 Published Online before print July 8, 2020

DOI 10.1212/WNL.0000000000009930

This information is current as of July 8, 2020

\section{Updated Information \& Services}

References

Citations

Subspecialty Collections

Permissions \& Licensing

Reprints including high resolution figures, can be found at: http://n.neurology.org/content/95/7/e781.full

This article cites 45 articles, 3 of which you can access for free at: http://n.neurology.org/content/95/7/e781.full\#ref-list-1

This article has been cited by 5 HighWire-hosted articles: http://n.neurology.org/content/95/7/e781.full\#\#otherarticles

This article, along with others on similar topics, appears in the following collection(s):

\section{Brain trauma}

http://n.neurology.org/cgi/collection/brain_trauma

\section{MRI}

http://n.neurology.org/cgi/collection/mri

Neuropsychological assessment

http://n.neurology.org/cgi/collection/neuropsychological_assessment

Information about reproducing this article in parts (figures,tables) or in its entirety can be found online at:

http://www.neurology.org/about/about_the_journal\#permissions

Information about ordering reprints can be found online:

http://n.neurology.org/subscribers/advertise

Neurology ${ }^{\circledR}$ is the official journal of the American Academy of Neurology. Published continuously since 1951, it is now a weekly with 48 issues per year. Copyright Copyright ( 2020 The Author(s). Published by Wolters Kluwer Health, Inc. on behalf of the American Academy of Neurology.. All rights reserved. Print ISSN: 0028-3878. Online ISSN: 1526-632X.

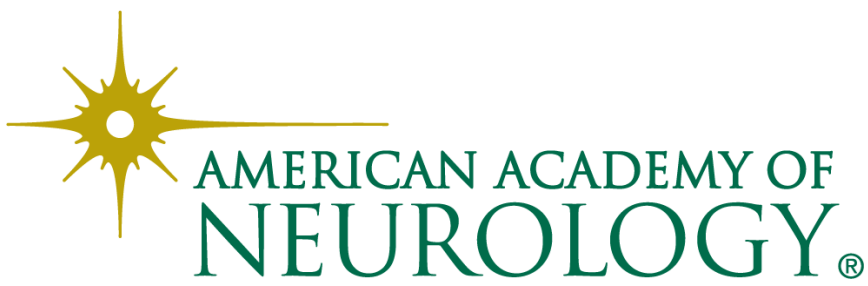

